\title{
Plasma exchange for thrombotic microangiopathy secondary to dermatomyositis associated with acute kidney injury and complement activation: a case report with literature review
}

\author{
Norifumi Hayashi ${ }^{\text {* }}$, Keiichirou Okada', Yuko Tsuruyama', Yu Kagaya', Sho Kumano', Yuki Ishikura², \\ Kiminobu Takeda ${ }^{2}$, Masayuki Nanbư ${ }^{2}$, Keiji Fujimoto ${ }^{1}$, Hiroki Adachi ${ }^{1}$ and Hitoshi Yokoyama
}

\begin{abstract}
Background: Thrombotic microangiopathy (TMA) in patients with connective tissue disease is rare but lifethreatening. In particular, the survival rate of patients with dermatomyositis (DM) that develop TMA is low. The effectiveness of plasma exchange (PEX) therapy is unclear for the treatment of TMA secondary to DM.

Case presentation: We describe a case of a 28-year-old woman who developed severe DM complicated by aspiration pneumonia from dysphagia and acute kidney injury. The patient was unresponsive to corticosteroids and intravenous immunoglobulin (IVIG) therapy and developed TMA. In this case, immunofluorescence of skin biopsy revealed that complement activation was involved in the pathogenesis of DM. After 6 PEX therapies, thrombocytopenia improved. She was successfully treated by intensive care and PEX therapy.
\end{abstract}

Conclusions: PEX therapy was effective to treat TMA secondary to DM associated with complement activation.

Keywords: Dermatomyositis, Thrombotic microangiopathy, Plasma exchange, Complement activation, ADAMTS13

\section{Background}

Dermatomyositis (DM) is an idiopathic inflammatory muscle disease with characteristic cutaneous manifestations such as a periorbital heliotrope rash with edema and violaceous eruption on the knuckles (Gottron's papules) [1]. Skin manifestations often accompany or precede muscle weakness, which is typically distributed symmetrically and proximally [2]. Thrombotic microangiopathy (TMA) in patients with connective tissue disease (CTD) is rare but lifethreatening. In particular, the survival rate of patients with DM that develop TMA is low, only $18.8 \%$ in a small case series study [3].

\footnotetext{
* Correspondence: nori924@kanazawa-med.ac.jp

${ }^{1}$ Department of Nephrology, Kanazawa Medical University, 1-1 Daigaku,

Uchinada, Ishikawa 920-0293, Japan

Full list of author information is available at the end of the article
}

For the treatment of corticosteroid-resistant DM, plasma exchange (PEX) therapy is not effective for muscle strength and functional capacity [4]. Furthermore, because the disease is rare, the effectiveness of PEX is unclear for the treatment of TMA secondary to DM.

Here, we describe a patient with DM accompanied by DM-associated TMA who survived by intensive care and PEX therapy.

\section{Case presentation}

A 28-year-old woman with no significant medical history was admitted to the dermatology department for the treatment of a rash and muscle pain. Eighteen days before admission, erythema appeared over the trunk, face, and extremities. Three days later, pain and weakness of the bilateral thigh muscles developed. The muscle weakness progressed including difficulty climbing stairs. On admission, physical examination revealed Gottron's

(c) The Author(s). 2019 Open Access This article is distributed under the terms of the Creative Commons Attribution 4.0 International License (http://creativecommons.org/licenses/by/4.0/), which permits unrestricted use, distribution, and reproduction in any medium, provided you give appropriate credit to the original author(s) and the source, provide a link to the Creative Commons license, and indicate if changes were made. The Creative Commons Public Domain Dedication waiver (http://creativecommons.org/publicdomain/zero/1.0/) applies to the data made available in this article, unless otherwise stated. 
papules on the metacarpophalangeal joints (Fig. 1), heliotrope rash, and muscular pain and weakness in the thighs and upper arms. Laboratory evaluation revealed elevated levels of creatine kinase (CK, $9823 \mathrm{U} / \mathrm{L}$ ) and myoglobin $(307.3 \mathrm{ng} / \mathrm{mL})$. Serum anti-PL-12 antibody, an anti-aminoacyl tRNA synthetase antibody, was weakly positive and anti-factor $\mathrm{H}$ antibodies were negative (Table 1). Magnetic resonance imaging (MRI) revealed high intensity in the lesions of the bilateral thigh muscles in T2-weighted and STIR (short tau inversion recovery) images (Fig. 2a, b). The pathological findings from a skin biopsy showed a perivascular infiltration of inflammatory cells in the superficial dermis (Fig. 2c), whereas in muscle biopsy, muscle fiber necrosis and inflammatory infiltrates were not observed. Immunofluorescence of the skin biopsy revealed deposition of IgM, fibrinogen, C3d, C4d, and C5b-9 on dermal vessels (Fig. 2d).

According to these findings, she was diagnosed with dermatomyositis (DM), and therapy was initiated with methylprednisolone pulse (1 g/day for 3 days). However, the response to this therapy was poor, her muscle weakness progressed, and she developed severe dysphagia. Therefore, intravenous immunoglobulin (IVIG) therapy (20 g/day for 3 days) was performed. She developed acute kidney injury (AKI) and was referred to our nephrology department. On the 18th day, continuous hemodiafiltration (CHDF) was initiated because of AKI with anuria, hyperkalemia, and hypermyoglobinemia. Furthermore, respiratory failure developed because of complications with aspiration pneumonia and exhausted respiratory muscles, and mechanical ventilation was started. Laboratory evaluation revealed marked thrombocytopenia and hemolytic anemia with fragmented erythrocytes. Her kidney injury and the instability of her consciousness suggested a diagnosis of thrombotic microangiopathy (TMA), and we initiated PEX therapy using fresh frozen plasma at the dose of

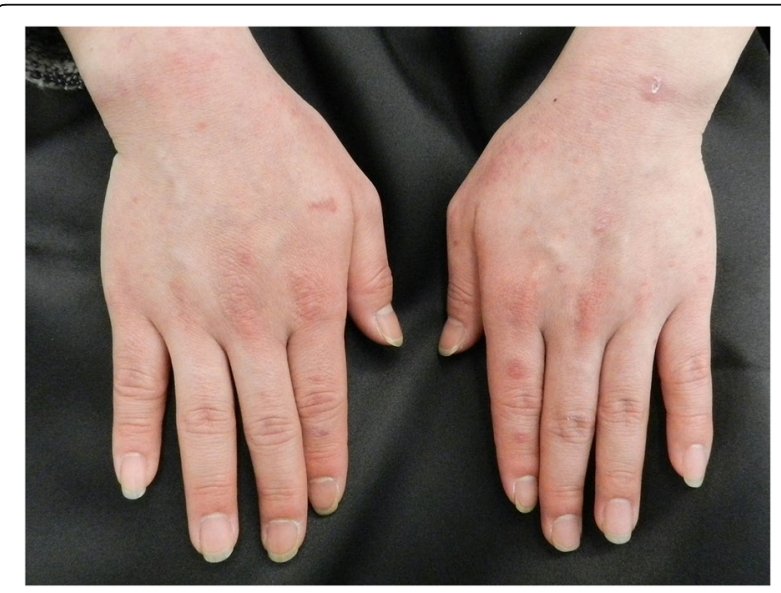

Fig. 1 A pathognomonic manifestation of dermatomyositis, Gottron's papule is seen on the metacarpophalangeal joints
1.5 times the estimated plasma volume (EPV). EPV was calculated from the equation given below [5],

$$
\begin{aligned}
\mathrm{EPV}(\mathrm{L})= & \text { body weight }(\mathrm{kg}) \times 0.065 \\
& \times(1 \text {-hematocrit })
\end{aligned}
$$

In PEX therapy, we used Plasmacure PE-05 (Kuraray Medical, Tokyo, Japan) as a plasma separator. In our case, body weight was $49.0 \mathrm{~kg}$ and hematocrit was 0.23 , respectively, as the initiation of PEX therapy.

Her clinical course is shown in Fig. 3. After 6 PEX therapies, thrombocytopenia improved. After pneumonia was resolved, azathioprine was added to oral prednisolone to control DM. On the 36th day, she was withdrawn from mechanical ventilation. Her urine volume recovered gradually, and hemodialysis therapy was discontinued on the 37th day. After long-term rehabilitation, her muscle strength gradually recovered, and she was discharged on the 200th day.

\section{Discussion and conclusions}

Our patient was diagnosed with DM by characteristic cutaneous manifestations, progressive muscle weakness, muscle enzyme elevation, and MRI findings. Although muscle biopsy revealed no characteristic features of DM, we considered this result was caused by sampling error. The patient was unresponsive to corticosteroids and IVIG in the first line therapy and developed TMA. However, immunosuppressive therapy was not increased because of aspiration pneumonia from dysphagia, which is frequently observed in severe DM [6].

The pathogenic mechanism underlying the relationship between DM and TMA is unclear. In the pathogenesis of DM, however, complement C5b-9 is activated and deposited on the endothelial cell wall of endomysial capillaries, which leads to necrosis, ischemia, and muscle fiber destruction [2]. Low-serum complement level and C5b-9 deposition on dermal vessels suggest that complement-mediated microvasculopathy was involved in the pathogenesis of DM and TMA in our patient.

Our patient did not exhibit a severe deficiency of ADAMTS13 activity (i.e., < 5\% of normal). For CTDassociated TMA, there are fewer patients who have a severe deficiency of ADAMTS13 activity (21\%) than patients who have a mild-to-moderate deficiency of ADMATS13 activity (79\%) [7]. In contrast to thrombotic thrombocytopenic purpura (TTP), most patients with CTD-associated TMA have high plasma levels of von Willebrand factor (VWF) and a mild-to-moderate deficiency of ADMATS13 activity [8].

For TTP treatment, survival rate improves markedly by PEX therapy [9]. PEX works by replenishing ADMATS13 and by removing ADAMTS13 inhibitors and UL-VWFM. The efficacy of PEX for the treatment 
Table 1 Laboratory data

\begin{tabular}{|c|c|}
\hline \multicolumn{2}{|l|}{ Hematology } \\
\hline WBC & 18,000 \\
\hline Neut & 92 \\
\hline Ly & 3 \\
\hline $\mathrm{RBC}$ & $268 \times 10^{4}$ \\
\hline Hemoglobin & 7.9 \\
\hline Platelet & 19,000 \\
\hline Fragmentation & + \\
\hline Haptoglobin & $<10$ \\
\hline \multicolumn{2}{|l|}{ ADAMTS13 } \\
\hline Activity & 17.8 \\
\hline Inhibitor & - \\
\hline Direct Coombs' test & - \\
\hline Indirect Coombs' test & - \\
\hline \multicolumn{2}{|l|}{ Biochemistry } \\
\hline TP & 6.0 \\
\hline Alb & 2.0 \\
\hline BUN & 32 \\
\hline Cre & 0.6 \\
\hline $\mathrm{Na}$ & 120 \\
\hline K & 6.1 \\
\hline $\mathrm{Cl}$ & 89 \\
\hline LDH & 1942 \\
\hline AST & 260 \\
\hline $\mathrm{ALT}$ & 138 \\
\hline CK & 9823 \\
\hline Myoglobin (@154.9) & 307.3 \\
\hline Ferritin (12-60) & 876 \\
\hline \multicolumn{2}{|l|}{ Serology } \\
\hline CRP & 0.27 \\
\hline $\mathrm{C} 3$ & 65 \\
\hline $\mathrm{C} 4$ & 14 \\
\hline $\mathrm{CH} 50$ & 32.6 \\
\hline ANA & $<40 x$ \\
\hline Anti-DNA Ab & - \\
\hline Anti-Jo-1 Ab & - \\
\hline Anti-ARS Ab & PL-12+ \\
\hline Anti-factor $\mathrm{H} \mathrm{Ab}$ & - \\
\hline \multicolumn{2}{|l|}{ Coagulation } \\
\hline PT-INR & 1.07 \\
\hline APTT (24-40) & 39.3 \\
\hline Fibrinogen & 252 \\
\hline FDP & 12.4 \\
\hline D-dimer & 5.74 \\
\hline Urinalysis & \\
\hline
\end{tabular}

Table 1 Laboratory data (Continued)

\begin{tabular}{|c|c|c|}
\hline $\mathrm{pH}$ & 5.5 & \\
\hline Protein & $1+$ & \\
\hline Glucose & - & \\
\hline Occult blood & $2+$ & \\
\hline \multicolumn{3}{|l|}{ Sediment } \\
\hline $\mathrm{RBC}$ & $10-19$ & /hpf \\
\hline WBC & $1-4$ & /hpf \\
\hline Cast & - & \\
\hline Myoglobin $(\leqq 10)$ & 110 & $\mathrm{ng} / \mathrm{mL}$ \\
\hline
\end{tabular}

of TMA of unclear etiology and without severe $\mathrm{g} / \mathrm{dL} \quad$ ADAMTS13 deficiency remains controversial [10-12]. $\mathrm{g} / \mathrm{dL} \quad$ For CTD-associated TMA, the efficacy of PEX is unclear $\mathrm{mg} / \mathrm{dL} \quad$ because of the lack of controlled prospective studies, but $\mathrm{mg} / \mathrm{dL}$ PEX is usually administered to eliminate UL-VWFM $\mathrm{mEq} / \mathrm{L}$ and activated complement factors and to replenish com$\mathrm{mEq} / \mathrm{L}$ plement regulatory factors. In our case, PEX was consid$\mathrm{mEg} / \mathrm{L}$ ered as effective in eliminating UL-VWFM caused by complement-mediated microvasculopathy and calming IU/L complement activation. Because an improvement of IU/L CTD is important for the treatment of CTD-associated IU/L TMA, PEX therapy combined with immunosuppressors, IU/L including glucocorticoids and cytotoxic agents, results in $\mathrm{ng} / \mathrm{mL}$ better outcomes [13].

In conclusion, we described a patient with severe dermatomyositis complicated by TMA who was successfully treated by intensive care and PEX therapy. Consid$\mathrm{mg} / \mathrm{dL}$ ering complement-mediated microvasculopathy as a $\mathrm{mg} / \mathrm{dL}$ pathogenic mechanism of DM, PEX therapy may be $\mathrm{mg} / \mathrm{dL} \quad$ highly effective in treating TMA secondary to DM.

$\mathrm{U} / \mathrm{mL}$

\section{Mini review}

TMA in connective tissue disease

Thrombotic microangiopathies (TMAs) are diseases characterized by microangiopathic hemolytic anemia, thrombocytopenia, and organ failure due to microvascular occlusions caused by platelet thrombi [14]. TMA is a pathological diagnostic term for pathological conditions exhibiting systemic microvascular thrombosis and vascular endothelial dysfunction. Japanese Society of Nephrology and Japan Pediatric Society developed diagnostic criteria for sec $\mathrm{mg} / \mathrm{dL}$ $\mu \mathrm{g} / \mathrm{mL}$ $\mu \mathrm{g} / \mathrm{mL}$ atypical hemolytic uremic syndrome (aHUS) [15]. In this diagnostic criterion in 2015, TMAs were classified according to their pathogenesis as follows: Shiga toxin-producing E. coli hemolytic uremic syndrome (STEC-HUS), TTP, atypical HUS (aHUS), and secondary TMA (Table 2). 

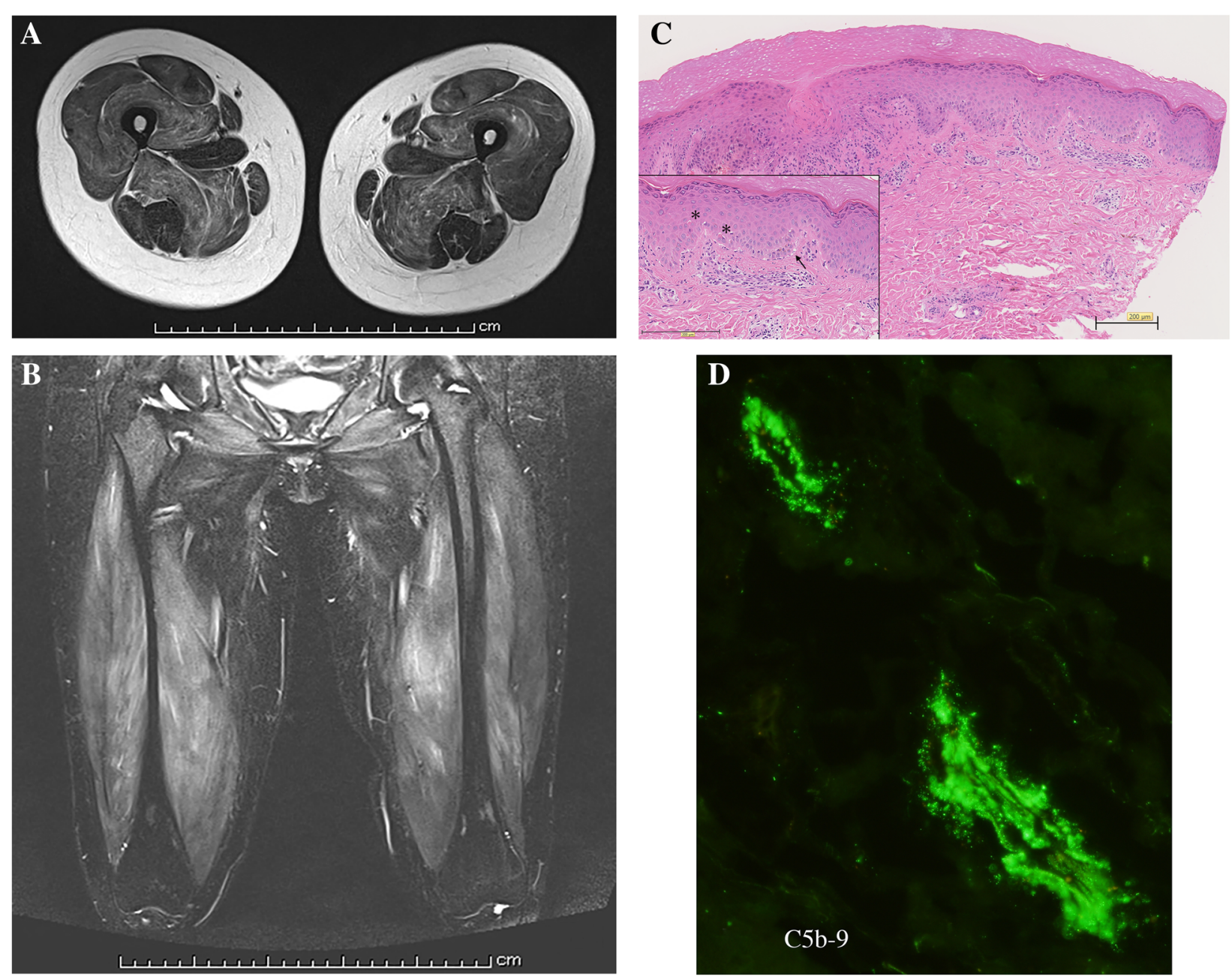

Fig. $2 \mathrm{MRI}$ and histological findings of the dermal biopsy. MRI showed high intensity in the lesions of the bilateral thigh muscles in T2-weighted (a) and short tau inversion recovery (b) imaging. In a skin biopsy, a perivascular infiltration of inflammatory cells in the superficial dermis, slight basal liquefaction degeneration (arrow), and some apoptotic cells (asterisk) in the epidermis were observed (c). C5b-9 deposits on the endothelial cell wall of the dermal vasculature (d)

In a Japanese registry of 919 TMA patients [7], CTDassociated TMA is the most common cause of secondary TMA (221 out of 382 patients, 57.8\%). In CTDassociated TMA, TMA complicated by systemic lupus erythematosus (SLE) is the most frequent (41.6\%) followed by systemic sclerosis (23.0\%) and polymyositis/ dermatomyositis (6.3\%).

TMA occurs in 3 to $9 \%$ cases of SLE patients [16]. The differential diagnosis of TMA with SLE patients includes malignant hypertension, antiphospholipid syndrome (APS)/catastrophic APS, TTP, and drug-induced TMA. Careful evaluation of peripheral blood smear is useful for the diagnosis of these clinical syndromes. The patients with SLE accompanied by malignant hypertension and TTP show fragmented red blood cells in peripheral blood smear [17].
In the management of CTD-associated TMA, treating underlying autoimmune disorders is important. Furthermore, in suspected cases, anticoagulation, corticosteroids, PEX therapy, and IVIG have been used. In some cases showing resistance for these conventional therapies, the efficacy of anti-C5 monoclonal antibody eculizumab has been reported [16, 18]. Eculizumab binds to the C5 complement with high affinity and blocks the assembly of C5b-9. Eculizumab has shown the effectiveness and been approved for the treatment of patients with aHUS [19]. However, the effectiveness of eculizumab for the treatment of TMA secondary to SLE is still controversial.

\section{The roles of complements in TMA}

Dysregulation of complement cascade plays a major role in the pathogenesis of TMAs. Complement is part of the 


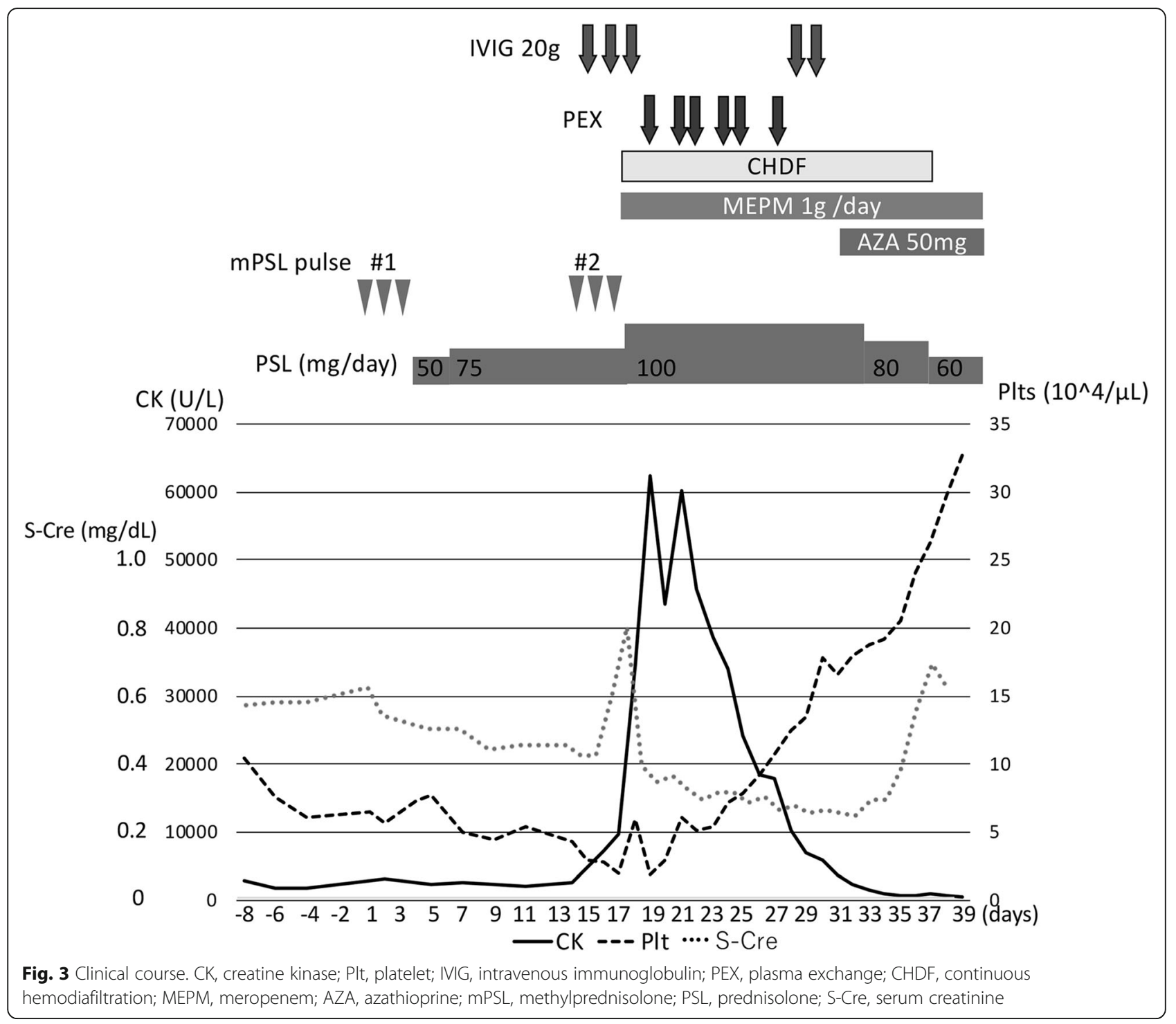

innate immune system and has three main physiologic activities, that is, defending against pyogenic bacterial infection, interfacing innate and adaptive immunity, and disposing of immune complexes and the products of inflammatory injury. Under normal circumstances, the regulatory mechanisms of complement are well balanced. For instance, complement attacks against invading pathogens, on the one hand, complement activation on normal cells and tissues are limited on the other hand [20]. Insufficient or excessive complement activity disturbs homeostasis and causes some diseases. These delicate balances are usually maintained by specific complement regulators.

Complement regulatory proteins inhibit complement activation both in the fluid phase and on membrane surface. Dysfunction or deficiency of some complement regulatory protein is associated with TMAs. aHUS is caused by genetic mutations in factor $\mathrm{H}$, factor I, membrane cofactor protein (MCP), C3, factor $\mathrm{B}$, and thrombomodulin [21]. Furthermore, in 6 to $10 \%$ of patients with aHUS have anti-Factor $\mathrm{H}$ autoantibodies (Table 3) $[22,23]$. Factor $\mathrm{H}$ is a soluble complement regulator of the alternative pathway by competing with factor $\mathrm{B}$ in binding to $\mathrm{C} 3 \mathrm{~b}$, by acting as a cofactor for factor I in inactivation of $\mathrm{C} 3 \mathrm{~b}$, and by enhancing dissociation of $\mathrm{C} 3$ convertase $[24,25]$. On endothelial cell surface, inactivation of deposited C3b to iC3b by concerted action of factor $\mathrm{H}$, factor I, and MCP prevents the progression of the C3b-amplification loop [25]. Dysfunction of Factor $\mathrm{H}$ by genetic mutation or anti-Factor $\mathrm{H}$ antibodies decreases the avidity of factor $\mathrm{H}$ to $\mathrm{C} 3 \mathrm{~b}$. These results in the progression of the C3b-amplification loop and finally 
Table 2 Classification of TMA

STEC-HUS
Infection with Shiga toxin-producing Escherichia coli or less frequently
with Shigella dysenteriae. The most common cause of HUS in children.
TTP
Deficiency of ADAMTS13 hereditary (Upshaw-Shulman syndrome) or
acquired that causes by ADAMTS13 inhibitor.
aHUS, complement regulation abnormality
Congenital
Genetic mutations of complement proteins
Acquired
Autoantibodies against complement proteins, such as anti-factor H
antibody
Secondary TMA
Cobalamin metabolism disorder
Drug-induced
Chemotherapeutic agents (e.g., gemcitabine, mitomycin)
Immunosuppressive agents (e.g., cyclosporine, tacrolimus)
Antiplatelet agents (e.g., ticlopidine)
Infection
Pneumococcus, human immunodeficiency virus, pertussis,
influenza, varicella
Pregnancy-related
Preeclampsia/eclampsia, hemolysis, elevated liver HELLP
Auto-immune disease, collagen disease
Systemic lupus erythematosus, systemic sclerosis, polymyositis/
dermatomyositis
Bone marrow transplant, organ transplant-related

Table 3 Complement abnormalities in aHUS

\begin{tabular}{ll}
\hline Form of aHUS & Complement abnormalities \\
\hline Familial & Mutations in factor $\mathrm{H}, 40-45 \%$ \\
& In factor I, 5-10\% \\
& In C3, 8-10\% \\
& In membrane cofactor protein, 7-15\% \\
& In thrombomodulin, 9\% \\
& In factor B, 1-2\% \\
Mutations in factor H, 15-20\% & In factor I, 3-6\% \\
In C3, 4-6\% \\
In membrane cofactor protein, 6-10\% \\
In thrombomodulin, 2\% \\
In factor B, 2 cases \\
Anti-Factor H antibodies, 6-10\% \\
\hline
\end{tabular}

leads to C5b-9 formation. C5b-9 formation on endothelial cells induces pore formation and leads to calciuminflux into the cells, metabolic activation, and membrane alterations. As a result, endothelial cells become swollen and detach from the vessel walls [21]. Combined with similar changes in platelets and leukocytes, an increase in procoagulant activity causes thrombosis [26].

\section{Abbreviations \\ aHUS: Atypical hemolytic uremic syndrome; AKl: Acute kidney injury; APS: Antiphospholipid syndrome; CHDF: Continuous hemodiafiltration; CTD: Connective tissue disease; DM: Dermatomyositis; EPV: Estimated plasma volume; IVIG: Intravenous immunoglobulin; MCP: Membrane cofactor protein MRI: Magnetic resonance imaging; PEX: Plasma exchange; SLE: Systemic lupus erythematosus; STEC-HUS: Shiga-toxin-producing E. coli hemolytic uremic syndrome; TMA: Thrombotic microangiopathy; \\ TTP: Thrombocytopenic purpura; UL-WWFM: Unusually large WWF multimers; WWF: von Willebrand factor}

\section{Acknowledgements}

Not applicable.

\section{Authors' contributions}

$\mathrm{NH}, \mathrm{KO}, \mathrm{YT}, \mathrm{YK}, \mathrm{SK}$, and $\mathrm{YI}$ took care of this patient. KT and MN evaluated the findings of skin biopsy. $\mathrm{NH}, \mathrm{KF}, \mathrm{HA}$, and $\mathrm{HY}$ analyzed and interpreted the patient data. $\mathrm{NH}$ and $\mathrm{HY}$ prepared this manuscript. All authors read and approved the final manuscript.

\section{Funding}

The authors declare that there is no funding related to this manuscript.

\section{Availability of data and materials}

The data and materials were all included in the manuscript.

\section{Ethics approval and consent to participate}

The case report was written in compliance with the Declaration of Helsinki.

\section{Consent for publication}

Agreement was obtained from the patient for publication of this case report.

\section{Competing interests}

The authors declare that they have no competing interests.

\section{Author details}

${ }^{1}$ Department of Nephrology, Kanazawa Medical University, 1-1 Daigaku, Uchinada, Ishikawa 920-0293, Japan. ²Department of Dermatology, Kanazawa Medical University, Uchinada, Japan.

Received: 13 May 2019 Accepted: 13 November 2019

Published online: 05 December 2019

\section{References}

1. Callen JP, Wortmann RL. Dermatomyositis. Clin Dermatol. 2006;24(5):363-73.

2. Dalakas MC. Inflammatory muscle diseases. N Engl J Med. 2015;372(18): 1734-47.

3. Yamada S, Yamashita H, Nakano M, Hatano H, Sasaki T, Takahashi Y, et al. Thrombotic microangiopathy with polymyositis/dermatomyositis: three case reports and a literature review. Intern Med. 2018;57(15):2259-65.

4. Miller FW, Leitman SF, Cronin ME, Hicks JE, Leff RL, Wesley R, et al. Controlled trial of plasma exchange and leukapheresis in polymyositis and dermatomyositis. N Engl J Med. 1992;326(21):1380-4.

5. Kaplan AA. A simple and accurate method for prescribing plasma exchange. ASAIO Trans. 1990;36(3):M597-9.

6. Marie I, Menard JF, Hatron PY, Hachulla E, Mouthon L, Tiev K, et al. Intravenous immunoglobulins for steroid-refractory esophageal involvement related to polymyositis and dermatomyositis: a series of 73 patients. Arthritis Care Res (Hoboken). 2010;62(12):1748-55. 
7. Fujimura Y, Matsumoto M. Registry of 919 patients with thrombotic microangiopathies across Japan: database of Nara Medical University during 1998-2008. Intern Med. 2010;49(1):7-15.

8. Matsuyama T, Kuwana M, Matsumoto M, Isonishi A, Inokuma S, Fujimura Y. Heterogeneous pathogenic processes of thrombotic microangiopathies in patients with connective tissue diseases. Thromb Haemost. 2009;102(2):371-8.

9. Rock GA, Shumak KH, Buskard NA, Blanchette VS, Kelton JG, Nair RC, et al. Comparison of plasma exchange with plasma infusion in the treatment of thrombotic thrombocytopenic purpura. Canadian Apheresis Study Group. N Engl J Med 1991;325(6):393-397.

10. Li A, Makar RS, Hurwitz S, Uhl L, Kaufman RM, Stowell CP, et al. Treatment with or without plasma exchange for patients with acquired thrombotic microangiopathy not associated with severe ADAMTS13 deficiency: a propensity score-matched study. Transfusion. 2016;56(8):2069-77.

11. Vesely SK, George JN, Lammle B, Studt JD, Alberio L, El-Harake MA, et al. ADAMTS13 activity in thrombotic thrombocytopenic purpura-hemolytic uremic syndrome: relation to presenting features and clinical outcomes in a prospective cohort of 142 patients. Blood. 2003;102(1):60-8.

12. George JN. Measuring ADAMTS13 activity in patients with suspected thrombotic thrombocytopenic purpura: when, how, and why? Transfusion. 2015:55(1):11-3.

13. Jiang H, An X, Li Y, Sun Y, Shen G, Tu Y, et al. Clinical features and prognostic factors of thrombotic thrombocytopenic purpura associated with systemic lupus erythematosus: a literature review of 105 cases from 1999 to 2011. Clin Rheumatol. 2014;33(3):419-27.

14. Moake JL. Thrombotic microangiopathies. N Engl J Med. 2002;347(8):589_ 600.

15. Sawai T, Nangaku M, Ashida A, Fujimaru R, Hataya H, Hidaka Y, et al. Diagnostic criteria for atypical hemolytic uremic syndrome proposed by the Joint Committee of the Japanese Society of Nephrology and the Japan Pediatric Society. Clin Exp Nephrol. 2014;18(1):4-9.

16. Kello N, Khoury LE, Marder G, Furie R, Zapantis E, Horowitz DL. Secondary thrombotic microangiopathy in systemic lupus erythematosus and antiphospholipid syndrome, the role of complement and use of eculizumab: case series and review of literature. Semin Arthritis Rheum. 2019;49(1):74-83.

17. Shah AA, Higgins JP, Chakravarty EF. Thrombotic microangiopathic hemolytic anemia in a patient with SLE: diagnostic difficulties. Nat Clin Pract Rheumatol. 2007;3(6):357-62.

18. de Holanda MI, Porto LC, Wagner T, Christiani LF, Palma LMP. Use of eculizumab in a systemic lupus erythemathosus patient presenting thrombotic microangiopathy and heterozygous deletion in CFHR1-CFHR3. A case report and systematic review. Clin Rheumatol. 2017;36(12):2859-67.

19. Verhave JC, Wetzels JF, van de Kar NC. Novel aspects of atypical haemolytic uraemic syndrome and the role of eculizumab. Nephrol Dial Transplant. 2014;29(Suppl 4):iv131-41.

20. Walport MJ. Complement. First of two parts. N Engl J Med. 2001;344(14): 1058-66.

21. Meri S. Complement activation in diseases presenting with thrombotic microangiopathy. Eur J Intern Med. 2013;24(6):496-502.

22. Jozsi M, Licht C, Strobel S, Zipfel SL, Richter H, Heinen S, et al. Factor H autoantibodies in atypical hemolytic uremic syndrome correlate with CFHR1/CFHR3 deficiency. Blood. 2008;111(3):1512-4.

23. Dragon-Durey MA, Loirat C, Cloarec S, Macher MA, Blouin J, Nivet $\mathrm{H}$, et al. Anti-factor $\mathrm{H}$ autoantibodies associated with atypical hemolytic uremic syndrome. J Am Soc Nephrol. 2005;16(2):555-63.

24. Noris M, Remuzzi G. Atypical hemolytic-uremic syndrome. N Engl J Med. 2009;361(17):1676-87.

25. Jokiranta TS, Jaakola VP, Lehtinen MJ, Parepalo M, Meri S, Goldman A Structure of complement factor $\mathrm{H}$ carboxyl-terminus reveals molecular basis of atypical haemolytic uremic syndrome. EMBO J. 2006;25(8):1784-94.

26. Peerschke El, Yin W, Ghebrehiwet B. Complement activation on platelets: implications for vascular inflammation and thrombosis. Mol Immunol. 2010; 47(13):2170-5

\section{Publisher's Note}

Springer Nature remains neutral with regard to jurisdictional claims in published maps and institutional affiliations.

\section{Ready to submit your research? Choose BMC and benefit from:}

- fast, convenient online submission

- thorough peer review by experienced researchers in your field

- rapid publication on acceptance

- support for research data, including large and complex data types

- gold Open Access which fosters wider collaboration and increased citations

- maximum visibility for your research: over $100 \mathrm{M}$ website views per year

At BMC, research is always in progress.

Learn more biomedcentral.com/submissions 